\title{
Herpes Zoster Infection of Maxillary Nerve in a Healthy Lady
}

\author{
Mohamad $A^{1}$, Wan Mohamad $W E^{2}$, Soleh $M N^{3}$, Mohamad $I^{4}$
}

\begin{abstract}
Herpes zoster infection (HZI) occurs as a result from previous exposure to varicella zoster virus and the disease recurred at later onset of life when patient are in immunocompromised state. The manifestation can be varies and in fact can involve all parts of dermatome distribution. We present a case of HZI involving the second division of trigeminal nerve which involved danger triangle of face that resolved after one week of intravenous acyclovir.
\end{abstract}

Kevwords: Herpes zoster infection, maxillary nerve, acyclovir

International Journal of Human and Health Sciences Vol. 02 No. 02 April'18 Page : 94-97

\section{Introduction}

Herpes zoster infection (HZI) involving the maxillary division of trigeminal nerve is a rare condition. ${ }^{1}$ It is an acute infection viral disease that characterized by inflammation of dorsal root ganglion or extra medullary cranial nerve ganglia that associated with vesicular eruptions of the skin or mucous membrane in an area supplied by the affected nerve. ${ }^{2}$ It occurs due to reactivation of varicella zoster virus (VZV) which lies dormant in the sensory ganglia after previous episode of chicken pox. ${ }^{3}$ It usually affects the middle-aged and elderly who is in immunocompromised state especially the one with underlying diseases such as human immunodeficiency virus (HIV), leukemia, diabetes mellitus, malignancy as well as patient who had physical trauma, surgical stress, immunosuppressive therapy or radiation therapy. ${ }^{4}$ Pathognomonic features of the disease are painful unilateral vesicular rash, usually confined to distribution of sensory nerve. Thoracolumbar trunk is the most commonly affected ${ }^{5}$, especially
T3 to L3. With regards to maxillofacial regions, trigeminal nerve is the most commonly involved, followed by glossopharyngeal and hypoglossal nerve. Ophthalmic dermatome is the most commonly affected, while the maxillary and mandibular dermatome involvements are less common. ${ }^{6}$

\section{Case report}

A 21-year-old healthy Malay lady, presented with rashes at right side of face 4 days prior to admission. It was preceded with pain over right eye and right upper gum one day prior. The rash started with papules (Figure 1) which then become vesicles and later on erupted into pustules. She denied of otalgia or facial asymmetry. Apart from that, she also had dysphagia to solid but still able to tolerate soft diet. There was no rash elsewhere. She sought treatment at clinic nearby at day 2 of illness whereby she was prescribed with tablet acyclovir $200 \mathrm{mg} 5$ times daily together with acyclovir cream for local application, painkiller and antihistamine, unfortunately the lesions was

1. Adam Mohamad, Department of Otorhinolaryngology-Head \& Neck Surgery, School of Medical Sciences, UniversitiSains Malaysia Health Campus, 16150 Kota Bharu and Department of Otorhinolaryngology, Hospital TengkuAmpuanAfzan, 25100 Kuantan, Pahang, Malaysia

2. Wan Emelda Wan Mohamad, Department of Otorhinolaryngology, Hospital TengkuAmpuanAfzan, 25100 Kuantan, Pahang, Malaysia

3. Mohd Najeb Soleh, Department of Otorhinolaryngology, Hospital TengkuAmpuanAfzan, 25100 Kuantan, Pahang, Malaysia

4. Irfan Mohamad, Department of Otorhinolaryngology-Head \& Neck Surgery, School of Medical Sciences, UniversitiSains Malaysia Health Campus, 16150 Kota Bharu, Malaysia

Correspondence to: Adam Mohamad, Department of Otorhinolaryngology-Head \& Neck Surgery, School of Medical Sciences, Universiti Sains Malaysia Health Campus, 16150 Kota Bharu, Kelantan, Malaysia, Email: persona522115@gmail.com 
getting worse. Due to worsening condition, she went to emergency department.

On examination, she was alert and conscious. Her vital signs were stable. There were erythematous patches involving right side of face along the right maxillary nerve distribution. There were few vesicles (Figure 2) and pustules involving mainly the right upper lip, right nose particularly the dorsum and right vestibules with crusting within (Figure 3). The right upper lip was swollen. Besides that, there was eye redness; however there was no mucopurulent discharge or blurring of vision. Oropharyngeal examination revealed whitish lesion over right hard palate and soft palate. Her facial nerve was intact. Otoscopic examinations were unremarkable.

The diagnosis of herpes zoster of right maxillary branch was established and she was started with intravenous acyclovir $500 \mathrm{mg}$ thrice daily, vaseline as emollient, tablet diclofenac $50 \mathrm{mg}$ thrice daily and tablet loratadine once daily. Her condition gradually improving and the lesion responded

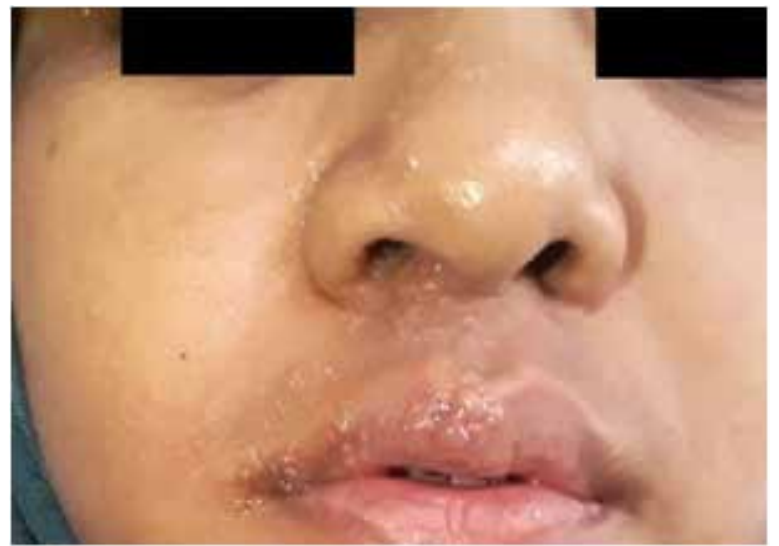

Figure 1: Lesion at right side of face on day 2 of illness

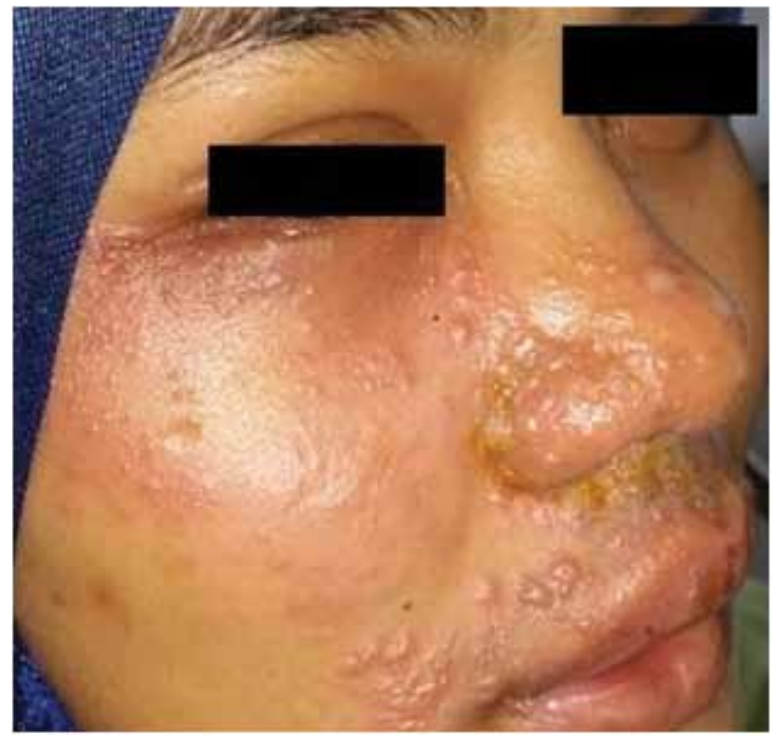

Figure 2: Patient condition during admission

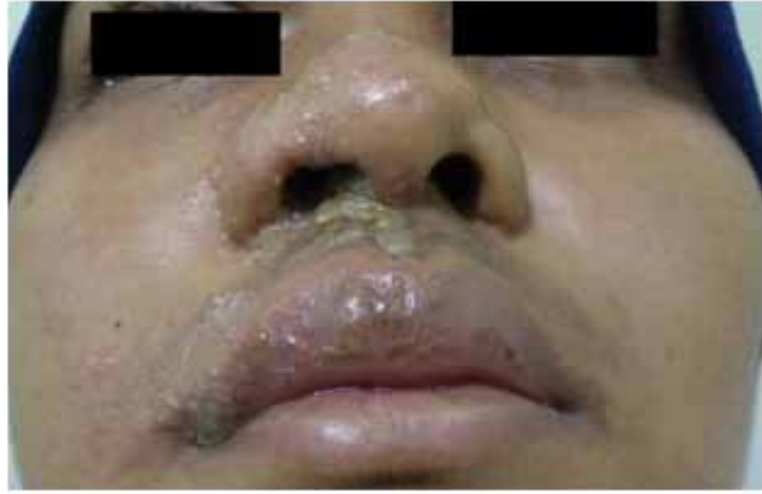

Figure 3: Crusting and swelling of the right vestibule (danger triangle of face).

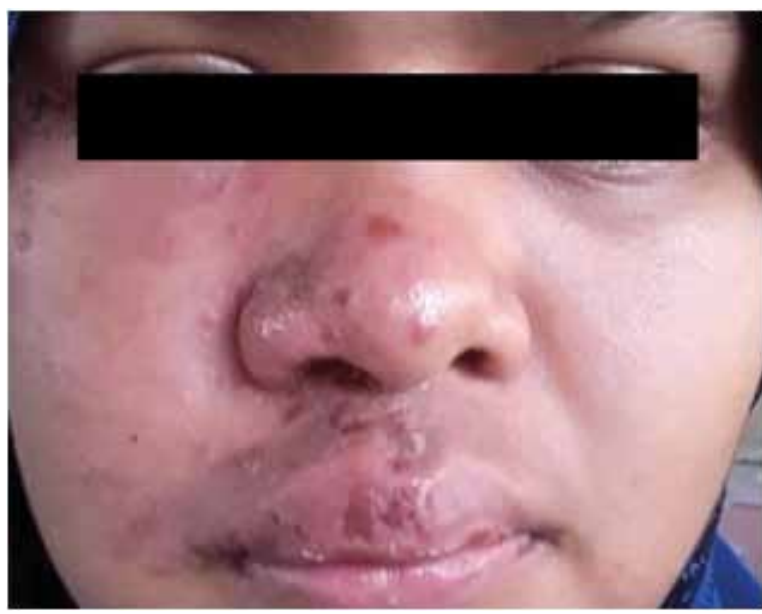

Figure 4: After 4 days of treatment

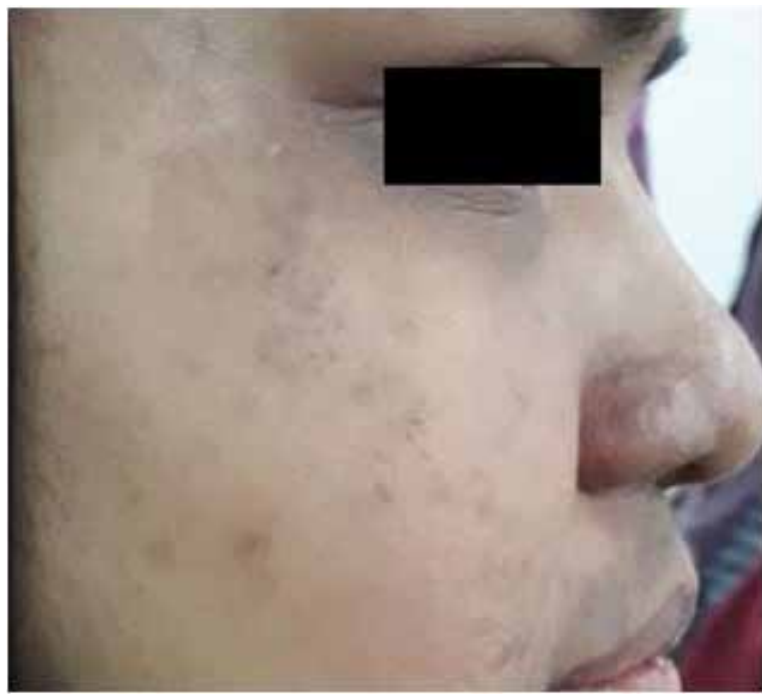

Figure 5: Patient's condition 3 weeks later; the lesion had completely resolved with only minimal scarring remained.

well to treatment and started to dry up (Figure 4). She was discharged home at day 7 of admission. Upon follow up 3 weeks later, the lesion and pain had completely resolved, however only minimal scarring remained (Figure 5) together with mild itchiness. 


\section{Discussion:}

VZV is the virus responsible for chicken pox in childhood. ${ }^{7}$ Upon resolution of the primary varicella infection, the remaining provirus segments travelled from the sensory nerve endings up and finally lodged in the cranial or dorsal root ganglia. Those viral fragments will then reside in neuronal or satellite cell nuclei, whereby they are protected from antibody that persist in circulation as a result of primary infection. This theory explained why herpes zoster usually affects the sensory ganglia and its dermatomal distribution. ${ }^{1}$ The virus remain latent inside the neuronal nucleus and does not multiply, however it can revert to an infectious state at any time especially when cellmediated immunity dropped. ${ }^{7}$

The risk factor such as stressful condition is likely the cause of VZV reactivation as at that time, she was sitting for her final exam. Generally, other potential risk factors for VZV reactivation includes prior VZV exposure (chicken pox), elderly, immunocompromised condition, immunosuppressive drugs, $\mathrm{HIV} /$ acquired immune deficiency syndrome (AIDS), bone marrow or organ transplantation, cancer, chronic steroid therapy and trauma. ${ }^{8}$

The diagnosis of herpes zoster is made clinically based on presence of prodromal pain, itching and typical zoster rashes. ${ }^{8}$ The prodromal pain usually begin 4 days to 2 weeks before the lesion appeared, which at times associated with paraesthesia at the region that will become zoster-affected dermatome. The pain could be either intermittent, throbbing, burning or shooting pain. ${ }^{9}$ Some of them experienced abnormal skin sensations such as tingling, dysesthesia and itching as well. ${ }^{10}$

Typical zoster rashes usually appeared proximally and then only spread to the affected dermatome. Initially, the lesions appear as erythematous papules, and then gradually turn to vesicles within 12 to 24 hours. ${ }^{8}$ The vesicles later become pustules in about 3 days and forming scabs 7 to 10 days later $^{10}$, which is demonstrated in our case.

The most significant complication of HZI is post herpetic neuralgia. Others include motor nerve palsy, optic neuropathy, blindness, encephalitis and facial scarring. ${ }^{5}$ Besides that, complications such as alveolar bone necrosis and rapid tooth exfoliation has been reported when there is involvement of either maxillary or mandibular division of trigeminal nerve. ${ }^{5}$

In this case, she only had minimal facial scarring.
Generally, HZI related pain resolves after about 90 days for many patients suffering it, unfortunately approximately $20 \%$ of them will have post herpetic neuralgia, which defined as pain persist for more than 3 months after rash had healed which requiring long term pain management. ${ }^{11}$ Given the incidence rate, all patients post HZI should be followed up for at least 3 months onwards after the rash settled. The treatment of HZI includes prompt initiation of antiviral treatment and adequate analgesic agents. Antivirals of choice are acyclovir, famciclovir or valacyclovir. ${ }^{12}$ This patient had been started with oral and topical acyclovir two days earlier, however the lesion get worsening. This could be due to high viral load at that time and oral acyclovir not that effective as compared to intravenous acyclovir. This could have been true as after the usage of intravenous acyclovir, the lesion started to dry up. A study was done by Bean at el, showing the effectiveness of intravenous acyclovir in treating acute herpes zoster ${ }^{13}$, however so far there is no study comparing effectiveness oral versus intravenous acyclovir in treating HZI in the literature. Apart from that, with the involvement of the lesion at the danger triangle of face in this case, more aggressive treatment with intravenous antiviral agent was given to prevent life-threatening cavernous sinus thrombosis. ${ }^{14}$

There has been reported case of HZI which causes orbital abscess and superior orbital fissure syndrome as well as cavernous sinus thrombosis. ${ }^{15}$ These antiviral agents can reduce the duration of viral shedding, fastening rash healing, reducing severity and duration of acute pain, as well as reduce risk of progression to post herpetic neuralgia when taken early in the course of infection. ${ }^{16}$

Aggressive treatment of HZI with antiviral drugs, glucocorticoid, opioid and non-opioid analgesics is recommended to prevent post herpetic neuralgia as these can reduce viral replications, inflammation and pain elimination respectively ${ }^{17}$, thus conservative management is not advisable though it is known to be non-contagious and selflimiting.

\section{Conclusion:}

Herpes zoster infection is a potential life threatening infection if there is delayed treatment such as when it involve danger triangle of face. Clinician has to recognize the early features of herpes zoster infection and provide prompt antiviral therapy to prevent the complications. 


\section{Reference:}

1. Paquin R, Susin LF, Welch G, Barnes JB, Stevens MR, Tay FR. Herpes zoster involving the second division of the trigeminal nerve: Case Report and Literature Review. Journal of Endodontics. 2017;43:1569-1573.

2. Arduino PG, Porter SR. Herpes Simplex Virus Type 1 infection: overview on relevant clinico-pathological features. Journal of Oral Pathology \& Medicine. 2008;37(2):107-121.

3. Barrett AP. Herpes zoster virus infection: A clinicopathologic review and case reports. Australian Dental Journal. 1990;35(4):328332.

4. Jain MK, Manjunath K, Jagadish S. Unusual oral complications of herpes zoster infection: report of a case and review of literature. Oral Surgery, Oral Medicine, Oral Pathology, Oral Radiology, and Endodontology. 2010;110(5):e37-e41.

5. Owotade FJ, Ugboko VI, Kolude B. Herpes zoster infection of the maxilla: case report. Journal of Oral and Maxillofacial Surgery. 1999;57(10):1249-1251.

6. Carbone V, Leonardi A, Pavese M, Raviola E, Giordano M. Herpes zoster of the trigeminal nerve: a case report and review of the literature. Minerva Stomatologica. 2004;53(1-2):49-59.

7. Arvin A. Aging, immunity, and the varicellazoster virus. New England Journal of Medicine. 2005;352(22):2266-2267.

8. Weinberg JM. Herpes zoster: epidemiology, natural history, and common complications. Journal of the American Academy of Dermatology. 2007;57(6):S130-S5.

9. Wood M, Easterbrook P. Shingles, scourge of the elderly: the acute illness. Clinical management of herpes zoster: IOS Press,
Washington (DC); 1995. p. 193-209.

10. Johnson RW, Whitton TL. Management of herpes zoster (shingles) and postherpetic neuralgia. ExpertOpiniononPharmacotherapy. 2004;5(3):551-9.

11. Takao Y, Miyazaki Y, Okeda M, Onishi F, Yano S, Gomi Y, et al. Incidences of herpes zoster and postherpetic neuralgia in Japanese adults aged 50 years and older from a community-based prospective cohort study: the SHEZ study. Journal of Epidemiology. 2015;25(10):617-625.

12. Siwamogstham P, Kuansuwan C, Reichart P. Herpes zoster in HIV infection with osteonecrosis of the jaw and tooth exfoliation. Oral Diseases. 2006;12(5):500-5.

13. Bean B, Braun C, Balfour H. Acyclovir therapy for acute herpes zoster. The Lancet. 1982;320(8290):118-121.

14. Zhang J, Stringer MD. Ophthalmic and facial veins are not valveless. Clinical \& Experimental Ophthalmology. 2010;38(5):502-510.

15. Lavaju P, Badhu BP, Shah S. Herpes zoster ophthalmicus presenting as orbital abscess along with superior orbital fissure syndrome: A case report. Indian Journal of Ophthalmology. 2015;63(9):733.

16. Sampathkumar P, Drage LA, Martin DP, editors. Herpes zoster (shingles) and postherpetic neuralgia. Mayo Clinic Proceedings; 2009: Elsevier.

17. Schmidt SA, Rowbotham MC. Aggressive Noninvasive Treatment of Acute Herpes Zoster for the Prevention of Postherpetic Neuralgia. In Herpes Zoster: Postherpetic Neuralgia and Other Complications 2017 (pp. 341-364). Springer International Publishing. 